\title{
Review: subglottic secretion drainage reduces ventilator associated pneumonia
}

Dezfulian C, Shojania K, Collard HR, et al. Subglottic secretion drainage for preventing ventilator-associated pneumonia: a metaanalysis. Am J Med 2005;118:11-8.

Does subglottic secretion drainage (SSD) prevent ventilator associated pneumonia (VAP) in critically ill patients?

\section{METHODS}

Data sources: Medline, CINAHL, EMBASE/Excerpta Medica,
Cochrane Library, Current Contents, and Biological Abstracts
(1966 to May 2003); reference lists of retrieved studies and
reviews; and authors of identified studies.
Study selection and assessment: randomised controlled trials
(RCTs) that compared SSD with no SSD in mechanically ventilated
patients and reported pneumonia as an outcome.
Methodological quality of individual studies was assessed based
on allocation concealment and blinding.
Outcomes: VAP. Secondary outcomes were mortality, intensive
care unit (ICU) length of stay (LOS), hospital LOS, ventilation
duration, and time from intubation to diagnosis of pneumonia.

\section{MAIN RESULTS}

5 RCTs $(n=896)$ met the selection criteria. SSD involved intermittent wall suction in 2 RCTs, continuous wall suction in 2 RCTs, and hourly syringe suction in 1 RCT. In 4 RCTs, patients were expected to be intubated for $>72$ hours. Patients who received SSD had reduced risk of VAP (table), required fewer days of mechanical ventilation (3 RCTs, $\{\mathrm{n}=683\}$, $\uparrow$ weighted mean difference [WMD] $-1.8 \mathrm{~d}, 95 \%$ CI -2.1 to -1.5 ), had a shorter ICU LOS ( 3 RCTs, $\{\mathrm{n}=683\}$, $\dagger$ WMD $-1.4 \mathrm{~d}$, CI -2.1 to -0.8 ), and developed pneumonia later (4 RCTs, $\{\mathrm{n}=746\}, \dagger$ WMD $3.1 \mathrm{~d}$, CI 2.7 to 3.4) than patients who received standard endotracheal tube care. Groups did not differ for mortality (table) or hospital LOS ( 2 RCTs, $\{\mathrm{n}=493\}$, $†$ WMD $-1.4 \mathrm{~d}, \mathrm{CI}-4.0$ to $1.2\} \dagger)$. A sensitivity analysis excluding 1 RCT in which patients could be ventilated $<72$ hours showed a similar reduction in VAP, but greater reductions in duration of mechanical ventilation ( 2 fewer $d$, CI 1.7 to 2.3) and ICU LOS (3 fewer d, CI 2.1 to 3.9), and prolonged time to development of pneumonia ( $7 \mathrm{~d}$ later, CI 5.5 to 8.1 ).

For correspondence: $\mathrm{Dr} C$ Dezfulian, 10 Center Drive, Building 10 Room 7D43, Bethesda, MD, USA. cdezfulian@cc.nih.gov

Sources of funding: Department of Veterans Affairs; Agency for Healthcare Research and Quality; and National Institutes of Health.

\section{CONCLUSION}

In critically ill patients, subglottic secretion drainage reduces ventilator associated pneumonia and decreases duration of mechanical ventilation and intensive care unit length of stay.

†Information provided by author.

\section{Commentary}

$\mathrm{V}$ $A P$ is clinically important because of its association with increased morbidity, mortality, and healthcare costs. ${ }^{.}$Early VAP is believed to result from aspiration of bacteria from the oropharynx, and therefore strategies that reduce oropharyngeal aspiration are of interest. ${ }^{2}$

Dezfulian et al present a rigorous meta-analysis of $5 \mathrm{RCTs}$ outlining the benefits of SSD. Important limitations of this meta-analysis are that only 1 trial had blinded outcome assessment, VAP was inconsistently defined, and all 5 trials used a different method for applying suction. Despite these limitations, all trials showed a statistically significant increase in time to development of pneumonia with SSD.

These findings generate additional questions for future research. Firstly, why did SSD have no effect on mortality? Despite the effectiveness of SSD in reducing early onset of VAP, further research is needed to identify strategies to reduce late onset VAP. Secondly, why did reduced ICU stay not affect overall hospital stay? This outcome was measured in only 2 RCTs and requires further investigation of post-ICU care and an economic evaluation of healthcare costs. Thirdly, although the effects of endotracheal suctioning on mucosal trauma have been documented for $>50$ years, ${ }^{3}$ what are the effects of SSD? Trials varied in their methods of applying suction to the subglottis in terms of pressure, duration, and interval. Dezfulian et al noted that no complications were reported in any of the trials, but adverse outcome indicators were not defined. Monitoring for evidence of bleeding or mucosal injury should be implemented to ensure safe practice.

The findings of this meta-analysis are important for nurses working in critical care. They suggest that SSD reduces VAP in patients ventilated for $>72$ hours and should be considered with other recommended strategies such as semi-recumbent positioning.

Bronagh Blackwood, RGN, RNT, PhD, DASE School of Nursing \& Midwifery, Queen's University Belfast Belfast, Northern Ireland, UK

1 Fagon JY, Chastre J, Hance AJ, et al. Am J Med 1993;94:281-8.

2 Collard HR, Saint S, Matthay MA. Ann Intern Med 2003;138:494-501.

3 Plum F, Dunning MF. N Engl J Med 1956;254:193-200.

Subglottic secretion drainage (SSD) v no SSD to prevent ventilator associated pneumonia*

\begin{tabular}{|c|c|c|c|c|c|}
\hline \multirow[b]{2}{*}{ Outcomes } & \multirow[b]{2}{*}{ Number of trials (n) } & \multicolumn{2}{|c|}{ Weighted event rates } & \multirow[b]{2}{*}{$\operatorname{RRR}(95 \% \mathrm{Cl})$} & \multirow[b]{2}{*}{ NNT (Cl) } \\
\hline & & SSD & No SSD & & \\
\hline \multirow[t]{2}{*}{$\begin{array}{l}\text { Ventilator associated } \\
\text { pneumonia }\end{array}$} & $5(896)$ & $12 \%$ & $19 \%$ & $49 \%$ (29 to 63 ) & $14(9$ to 31$)$ \\
\hline & & & & RRI (CI) & NNH \\
\hline Mortality & $4(823)$ & $16.5 \%$ & $16.3 \%$ & $7 \%(-19$ to 42$)$ & Not significant \\
\hline
\end{tabular}

*Abbreviations defined in glossary. Weighted event rates, RRR, RRI, NNT, NNH, and Cl calculated from data in article using a fixed effects model. Follow up was to discharge or death. 